\title{
Comparative Study between Intralesional and Topical Botulinum Toxin A Combined with Fractional Carbon Dioxide Laser in Treatment of Hypertrophic Scars and Keloids (Comparative study)
}

\author{
H.H.Sabry, A.M. Hamed and E.A.Ibrahim \\ Dermatology, Venereology and Andrology Dept., Faculty of Medicine, Benha Univ., Benha, Egypt \\ E-Mail:doctor_emy2003@yahoo.com
}

\begin{abstract}
Keloids and hypertrophic scars (HTS) are pathological scars that occur as a result of dermal injury and are characterized by persistent inflammation and fibrosis and excessive deposition of collagen and other fibroblast-derived extracellular matrix(ECM) proteins during skin healing.. Keloids Also hypertrophic scars representable an unreasonable tissue light of dermal damage described Toward nearby fibroblast burgeoning Furthermore overproduction of collagen. The point of this fill in is on analyze between the viability for intralesional versus topical anesthesia botulinum poison a joined together with fragmentary co2 laser in the medication of hypertrophic scars and keloids. This prospective clinical investigation included 10 patients with Keloids Also HTSs with no historical backdrop about medication six months former of the contemplate. Those whole scar lese greatness might have been partitioned under two halves. Person A large portion might have been dealt with with intralesional infusion for botulinum poison sort a once An month to an aggregate time of two months. The an alternate A large portion of the scar might have been approached with An course about two sessions from claiming co2 laser help at particular case month trailed Eventually Tom's perusing topical anesthesia requisition from claiming botulinumtoxin a for a catch up time of four months. Advanced photographas might have been performed for each tolerant previously, then after medicine.
\end{abstract}

Keywords: hypertrophic scars, keloids, fractional CO2 laser, botulinum toxin type A.

\section{Introduction}

Those oversaw economy about unreasonable scarring remains a test. There need aid Various medications accessible incorporate surgical excision, intralesional steroid injection, radiation therapy, lasers What's more weight therapy, However none for them offer acceptable restorative comes about. Those mossycup oak significant component may be counteractive action. Avoiding the sum unnecessary wounds, particularly done keloids-prone patients, remains a clear At blemished result [1]. Fragmentary co2 laser need been recommended as An guaranteeing intends for those change of keloids and hypertrophic scars. Fragmentary co2 laser $(10.600 \mathrm{~nm})$ will be a noninvasive medication that utilization a gadget with convey An laser shaft partitioned under many minute medicine zones that target An portion of the skin In the long run. Fragmentary laser medicine meets expectations at both those epidermal Also dermal layers of the skin [2]. Botulinum poison sort a could minimize facial scarring Toward handling progressions in the muscle spindles, that Might prompt modified tactile information Also transforms in the Mobile cycle dissemination for fibroblasts determined starting with the hypertrophic scar [3].

\section{Patients and methods}

This contemplate incorporated ten patients for hypertrophic scars What's more keloids who went to our dermatology outpatient facility. Those study might have been evaluated and endorsed by the regulate morals panel. At patients for no past clinical intercession in the A six months were included in the contemplate. Know patients underwent historical backdrop taking Furthermore clinical examination. Prohibition criteria were pregnancy, lactation, neighborhood infection, pre- existing neuromuscular alternately hypersensitive response to botulinum poison. The whole scar lese greatness might have been partitioned under two halves. Person half might have been treated with intralesional infusion about botulinum poison sort a (Botox Allergan ®, Irvine, CA, usa. $100 \mathrm{u}$ vacuum-dried powder On An single-use vial to reconstitution weakened done $2 \mathrm{ml}$ for sterile, preservative-free $0.9 \%$ saline on constitute an answer In a fixation about $4 \mathrm{U} / 0.1 \mathrm{~mL}$ ) might have been administered once a month to an aggregate time from claiming two months. Those an additional half of the scar might have been dealt with for a course about two sessions from claiming $10.600 \mathrm{~nm}$ fragmentary co2 (Smartxide DOT, propelled co2 fragmentary technology, DEKA, Florence, Italy) for energy 20(w), stay the long run 800(us), Furthermore dividing 600 (um) to keloids same time those force $12(\mathrm{w})$, stay run through (400(us), and dividing 600(um) were utilized within hypertrophic scars. Three passes were performed till arriving at the clinical endpoint which is gentle erythema taken after by topical anesthesia requisition of botulinum poison a.

At the 4th month catch up period, the Generally speaking evaluation data might have been gotten Furthermore graded subjectively around vancouver scar scale.

\subsection{Statistical analysis}

The collected data was revised, coded, tabulated and introduced to a PC using Statistical package for Social Science (IBM Corp. Released 2011. IBM SPSS Statistics for Windows, Version 20.0. Armonk, NY: IBM Corp.). Data were presented and suitable analysis was done according to the type of data obtained for each parameter. Parametric data were expressed as mean \pm standard deviation and nonparametric data 
were expressed as numbers and percentages of the total.

All tests were 2 -sided and a $\mathrm{P}$-value $\leq 0.05$ was considered statistically significant.

\section{Results}

The study enrolled 6 males and 4 females with a mean age of $16.5 \pm 4.3$ years (range $5-20$ years). The mean duration of the scars was $1.1 \pm 0.3$ years

There was a significant difference between HTS scar characteristics at baseline and after completion of the treatment protocol (after intralesional botulinum toxin A treatment, as well as after Fractional CO2 laser combined with topical botulinum toxin A) in vascularity $(\mathrm{p}<0.05)$ Table $(1)$.

There was a significant difference between keloid scar characteristics at baseline and after completion of intralesional botulinum toxin A the treatment protocol in vascularity $(p<0.05)$. In addition, there was a significant difference between scar characteristics at baseline and after completion of Fractional CO2 laser treatment protocol combined with topical botulinum toxin A in vascularity only $(\mathrm{p}<0.05)$ (Table 2$)$.

Table (1) Comparison of VSS after treatment when compared to before treatment in HTS cases.

\begin{tabular}{|c|c|c|c|c|c|}
\hline & \multicolumn{5}{|c|}{ HTS } \\
\hline & $\begin{array}{c}\text { Before } \\
\text { treatment }\end{array}$ & $\begin{array}{c}\text { After } \\
\text { Intralesional } \\
\text { botulinum } \\
\end{array}$ & & $\begin{array}{c}\text { After Fractional } \\
\text { CO2 laser + topical } \\
\text { botox }\end{array}$ & \\
\hline & & toxin $\mathrm{A}$ & $\mathbf{P}$ & & $\mathbf{P}$ \\
\hline & mean \pm SD & mean \pm SD & & mean \pm SD & \\
\hline Vascularity & $0.8 \pm 0.13$ & $0.2 \pm 0.07$ & 0.003 & $0.1 \pm 0$ & 0.001 \\
\hline Pigmentation & $1.4 \pm 0.2$ & $1.1 \pm 0.1$ & 0.08 & $0.9 \pm 0.3$ & 0.082 \\
\hline Pliability & $2.5 \pm 0$ & $2.2 \pm 0.4$ & 0.73 & $2.2 \pm 0.24$ & 1.1 \\
\hline Height & $1.5 \pm 0.6$ & $1.3 \pm 0.8$ & 1.2 & 1.4 & 2.03 \\
\hline Total score & $6.2 \pm 0.93$ & $4.8 \pm 1.37$ & 0.07 & $4.6 \pm 0.5$ & 0.09 \\
\hline
\end{tabular}

Table (2) Comparison of VSS after treatment when compared to before treatment in keloid cases.

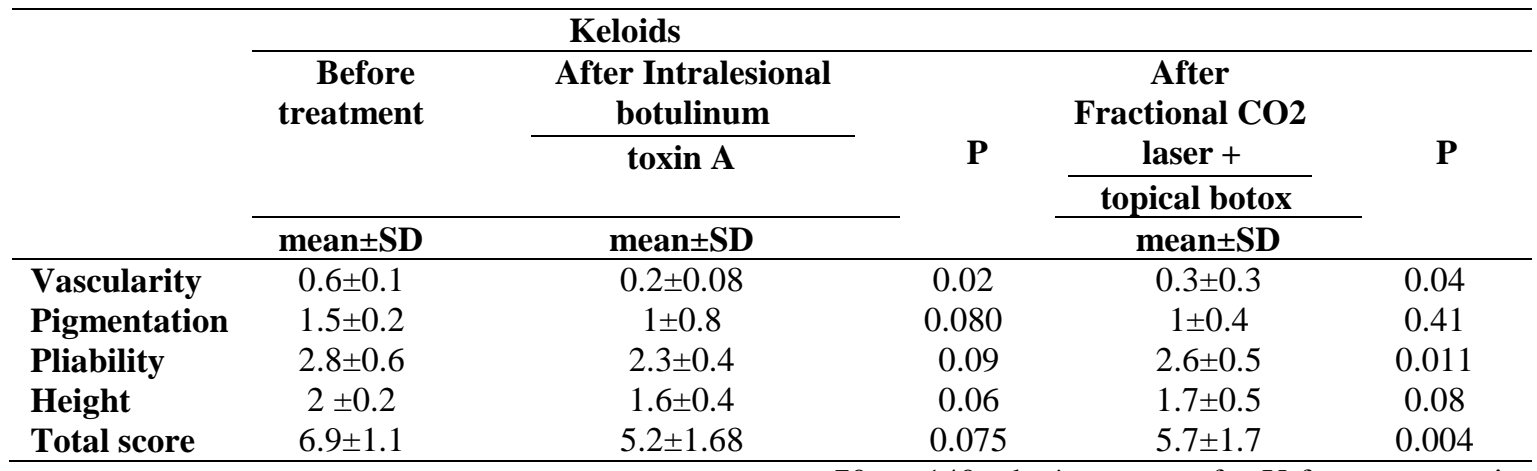

\section{Discussion}

This randomized similar study might have been directed for dermatology and andrology Branch for Benha college hospitals, those investigation might have been conveyed ahead 10 patients with hypertrophic scars Furthermore keloids. In the available study, both HTS Furthermore keloid instances treated

with intralesional botulinum poison a demonstrated noteworthy change for vascularity At contrasted with preceding medication.

This hails in understanding for those study for Zhibo What's more Xiaobo, (2009) who contemplated 12 patients with keloid lesions dealt with for intralesional botulinum poison sort a. BTX-A might have been provided for at An fixation about $35 \mathrm{U} / \mathrm{mL}$ (the aggregate measurements fluctuating starting with
70 on 140 what's to come for U for every session) with 3-month intervals for a greatest for 9 months. During 1

quite a while follow-up, the restorative results were fantastic over 3 patients $(25 \%)$, beneficial done 5 patients (41. 7\%), Also reasonable for 4 patients (33. $3 \%)$. Those level for tolerant fulfillment might have been high with no patients falling flat help or demonstrating to indications from claiming recurrence [4].

Our effects were not steady for Gauglitz et al. (2012) who contemplated four patients for keloid lesions. BTX injections were performed each 2 months for 6 months and the comes about were analyzed. Goal assessment of BTX-treated keloids utilizing optical profilometry didn't uncover At whatever progressions then afterward BTX help compared with benchmark. The Contrast for our consider might be expected of the 
different doses of injection, distinctive the long haul intervals and the next to no amount for patients [5].

Those activity of botulinum poison sort a for hypertrophic scars is accepted with a chance to be An transitory denervation about smooth muscle cell fibers diminishing those pressure in the scar tissue. This will be a standout amongst the principle elements that focus those degree about scar shaping [6].

Over HTS cases, noteworthy diminishment in VSS might have been watched. It might have been basically inferred starting with change in vascularity, likewise in keloid cases, huge change to vascularity might have been watched.

Laser helped drug conveyance may be a interesting ablative modality that need the capacity should obliterate those stratum corneum, epidermal, Furthermore dermal layers of the skin clinched alongside An predictable Also regulated way permitting a more stupendous profundity of infiltration by topknot connected medications, additional productive transcutaneous conveyance of extensive drug molecules, Furthermore actually systemic medication regardless organization by means of An transcutaneous course [7].

Altogether mulled over groups, score change might have been fundamentally higher done HTS over those change for keloids. It might a chance to be identified with those histopathological contrasts the middle of two scar sorts.

This goes in understanding for Al-Mohamady et al. (2016) done which there might have been noteworthy change On vascularity, pigmentation, pliability, tallness Also aggregate score then afterward medicine in HTS over over keloids [8].

\section{Conclusion}

In conclusion, BTX-A represents a novel, promising therapeutic agent for the treatment of hypertrophic scars and keloids with no side effects noted so far.
This study concludes that fractional laser followed by topical application of botulinum toxin A in HTS is also promising in treatment of HTS.

\section{References}

[1] T. Alster, E. Tanzi , Hypertrophic scars and keloids etiology and management. Am J Clin Dermatol, Vol. 4 (4),PP. 235-243, 2003.

[2] H.H. Sabry, S.H. Abdel Rahman, M.S. Hussein, The efficacy of combining Fractional Carbon Dioxide Laser with Verapamil Hydrochloride or 5Fluorouracil in the treatment of hypertrophic scars and keloids. Dermatologic Surgery, Vol. 45(4), PP. 536-546, 2006.

[3] X. Zhibo, Z. Miaobo, Botulinum toxin type A affects cell cycle distribution of fibroblasts derived from hypertrophic scar.

J Plast Reconstr Aesthet Surg, Vol.61(9), PP.11281129, 2008.

[4] X. Zhibo, Z. Miaobo , Intralesional botulinum toxin type A injection as a new treatment measure for keloids. Plast Reconstr Surg, Vol.124, PP.275e277e, 2009.

[5] G.G. Gauglitz, D. Bureik, Y. Dombrowski, Botulinum toxin A for the treatment of keloids. Skin Pharmacol Physiol, Vol.25, PP.313-8,2012.

[6] A.R. Scheffer, C. Erasmus, K. van Hulst Efficacy, duration of botulinum toxin treatment for drooling in 131 children. Arch Otolaryngol Head Neck Surg, Vol.136, PP.873-7, 2010.

[7] L.R. Sklar, C.T. Burnett, J.S. Waibel, Laser assisted drug delivery: A review of an evolving technology.Lasers Surg Med, Vol.46(4), PP.249262,2014.

[8] Ael-S. Al-Mohamady, S.M. Ibrahim, M.M. MuhammadPulsed dye laser versus long-pulsed $\mathrm{Nd}$ :YAG laser in the treatment of hypertrophic scars and keloid A comparative randomized splitscar trial. J Cosmet Laser Ther, Vol.18(4), PP.208-12,2016. 